\title{
A Paradigm Change in the Treatment Strategy for Hepatocellular Carcinoma
}

\section{Masatoshi Kudo}

Department of Gastroenterology and Hepatology, Kindai University Faculty of Medicine,

Osaka-Sayama, Japan

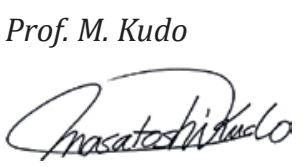

Editor Liver Cancer

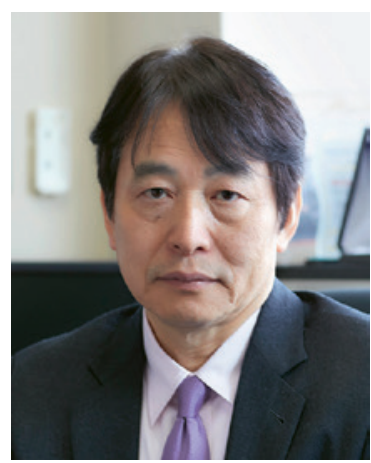

\section{Keywords}

Hepatocellular carcinoma · Treatment strategy

Japan has the best treatment outcomes for hepatocellular carcinoma (HCC) worldwide $[1,2]$. The 20th Nationwide Follow-Up Survey of Primary Liver Cancer in Japan reported a median survival time of 61 months, a 5 -year survival rate of $50.4 \%$, and a 10 -year survival rate of $24 \%$ among 65,711 patients with HCC whose data were compiled from approximately 600 institutions across Japan between 2002 and 2009 [3]. The survey included patients of all stages, ranging from single very-early-stage HCC of $2 \mathrm{~cm}$ or smaller, to advanced-stage HCC with vascular invasion or extrahepatic spread, to terminal-stage Child-Pugh C HCC. Establishment of a nationwide surveillance system of patients at a high risk of progressing from hepatitis C- or B-related cirrhosis to HCC in Japan has enabled HCC to be detected at an early stage ( $\leq 3$ tumors of $\leq 3 \mathrm{~cm}$ each, or a single tumor $\leq 5 \mathrm{~cm}$ ) in more than $60 \%$ of patients, most of whom undergo potentially curative treatment such as resection or ablation. About $30 \%$ of patients whose HCC is detected at an intermediate stage undergo transarterial chemoembolization (TACE). The remaining $10 \%$ of patients have advanced HCC with vascular invasion or extrahepatic spread or terminal-stage disease with Child-Pugh C liver function at the time of diagnosis. 
Advanced HCC with vascular invasion has been actively treated with hepatic arterial infusion chemotherapy in Japan [4]. Now that Japan's surveillance system is so well established, there is a sense that the best possible treatment outcomes of resection, local ablation therapy, and TACE have been achieved. Therefore, a recent trend is that systemic therapy including combination immunotherapy being introduced into the treatment for intermediate and advanced stage HCC is going to bring the new era in the treatment of HCC.

\section{Molecular Targeted Agents}

Sorafenib, the first molecular targeted drug to show a survival benefit in patients with advanced HCC, was approved worldwide in 2007 based on the results of the Sorafenib Hepatocellular Carcinoma Assessment Randomized Protocol (SHARP) trial [5] and the Asia-Pacific trial [6]. Since then, several phase III trials of molecular targeted drugs have been conducted; however, the 10-year period from 2007 to 2016 was a difficult time for the development of new HCC drugs because all the clinical trials ( 8 of first-line therapies and 5 of second-line therapies) conducted during that period failed (Table 1) [4-28]. This was followed by successful trials of regorafenib as a second-line therapy in 2017 [23], lenvatinib as a first-line therapy in 2018 [14], and ramucirumab [27] and cabozantinib [26] as second-line therapies in 2019. The approval of these targeted drugs resulted in a total of 5 new drug options (2 firstline and 3 second-line agents). In addition, recently the phase III IMbrave trial (atezolizumab plus bevacizumab combination therapy) has shown positive results [17]. These developments are greatly shifting the paradigm of HCC treatment.

\section{Paradigm Change in Intermediate-Stage HCC}

The biggest changes are occurring in the management of intermediate- and advancedstage HCC. Intermediate-stage HCC is generally defined as multifocal HCC ( $\geq 4$ tumors) or large HCC (tumor $>5 \mathrm{~cm}$ ). TACE was previously the only standard treatment option for this stage of disease; however, the 2017 version of the Clinical Practice Guidelines for Hepatocellular Carcinoma published by the Japan Society of Hepatology (JSH) [29] included not only TACE but also resection, hepatic arterial infusion chemotherapy, and molecular targeted therapy as recommended options for multifocal HCC and/or large HCC. Most notably, the concept of TACE-refractory HCC, first proposed by the JSH in 2010 [30] and later updated [31], was an important milestone. Subsequently, the concept of TACE-refractory HCC was adopted worldwide [32-35]. Sorafenib was not originally indicated for intermediate-stage HCC in some Asian countries; however, even those countries' health insurance systems were changed when the concept of TACE-refractory HCC was described in the Japanese Consensus-Based Clinical Practice Guidelines for Hepatocellular Carcinoma [30, 31]. In addition, 2 retrospective clinical studies showed that switching to molecular targeted therapy from TACE in refractory patients extended survival compared with repeating TACE [36, 37]. The OPTIMIS trial [38, 39], a noninterventional prospective global study conducted to validate the results of the retrospective studies, also showed that survival was extended by switching to a molecular targeted therapy after a patient had become refractory to TACE $[38,39]$. It is now nearly the global consensus that TACE-refractory patients should be promptly switched to molecular targeted therapy.

Another important option in intermediate-stage HCC is a combination strategy of TACE with molecular targeted agents. After 5 negative trials [40-44], the TACTICS trial clearly showed that TACE combined with sorafenib improved progression-free survival, which was specifically defined based on the concept of unTACEable progression $[45,46]$. 


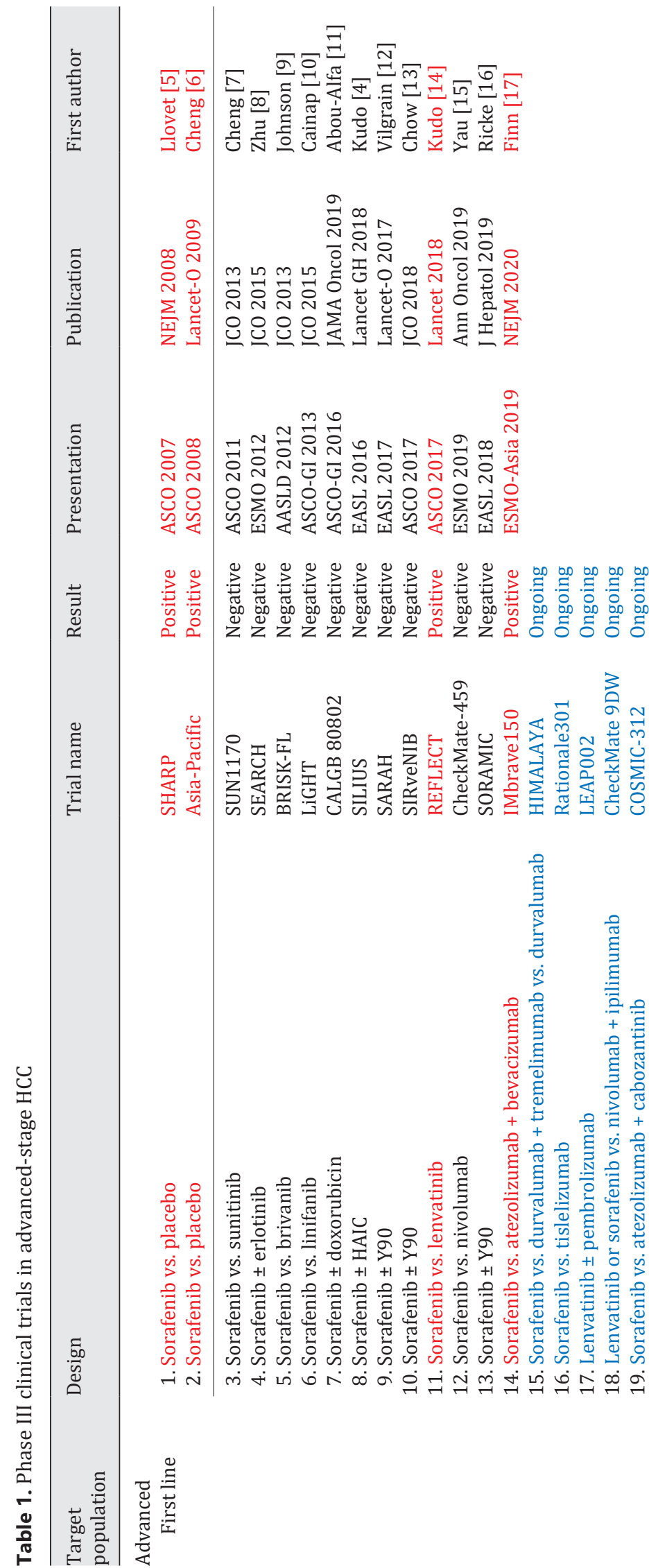

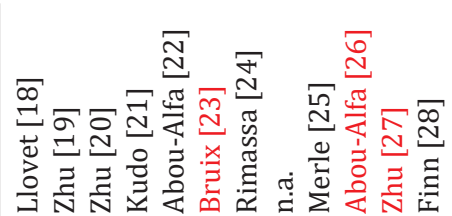
m

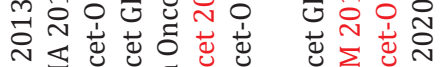

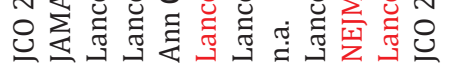

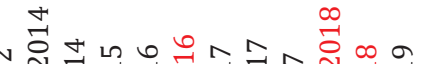

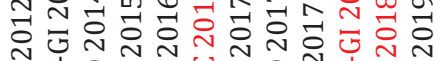

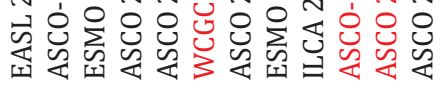

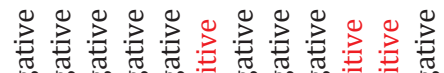

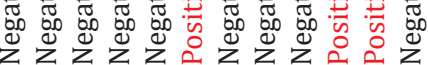

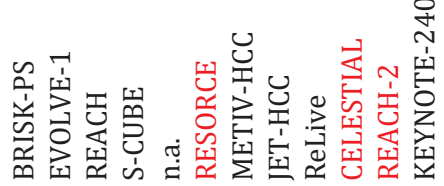


Changing paradigm for treatment strategy in intermediate-stage HCC with high tumor burden
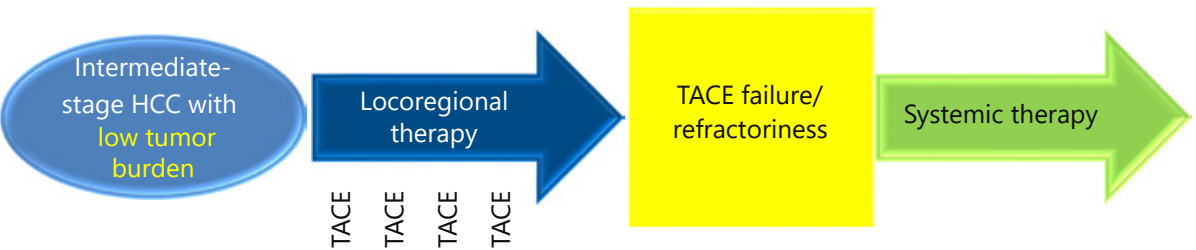

Intermediate-

stage HCC with

high tumor

burden
Systemic therapy (LEN)

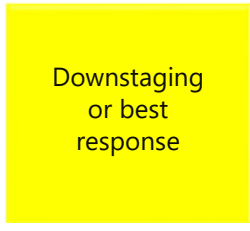

* Resection or ablation can be applied if downstaging is obtained by lenvatinib.

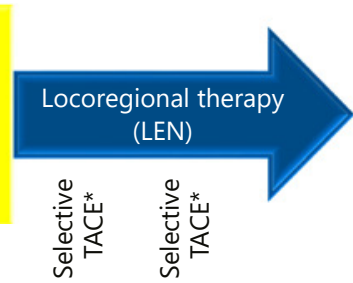

Fig. 1. Changing paradigm for treatment strategy in intermediate-stage HCC with high tumor burden. Until recently, transarterial chemoembolization (TACE) was only the standard of care for intermediate-stage HCC. However, first-line lenvatinib followed by locoregional therapy such as selective TACE, resection, or ablation may be a suitable treatment option for intermediate-stage HCC with high tumor burden. pts, patients; LEN, lenvatinib.

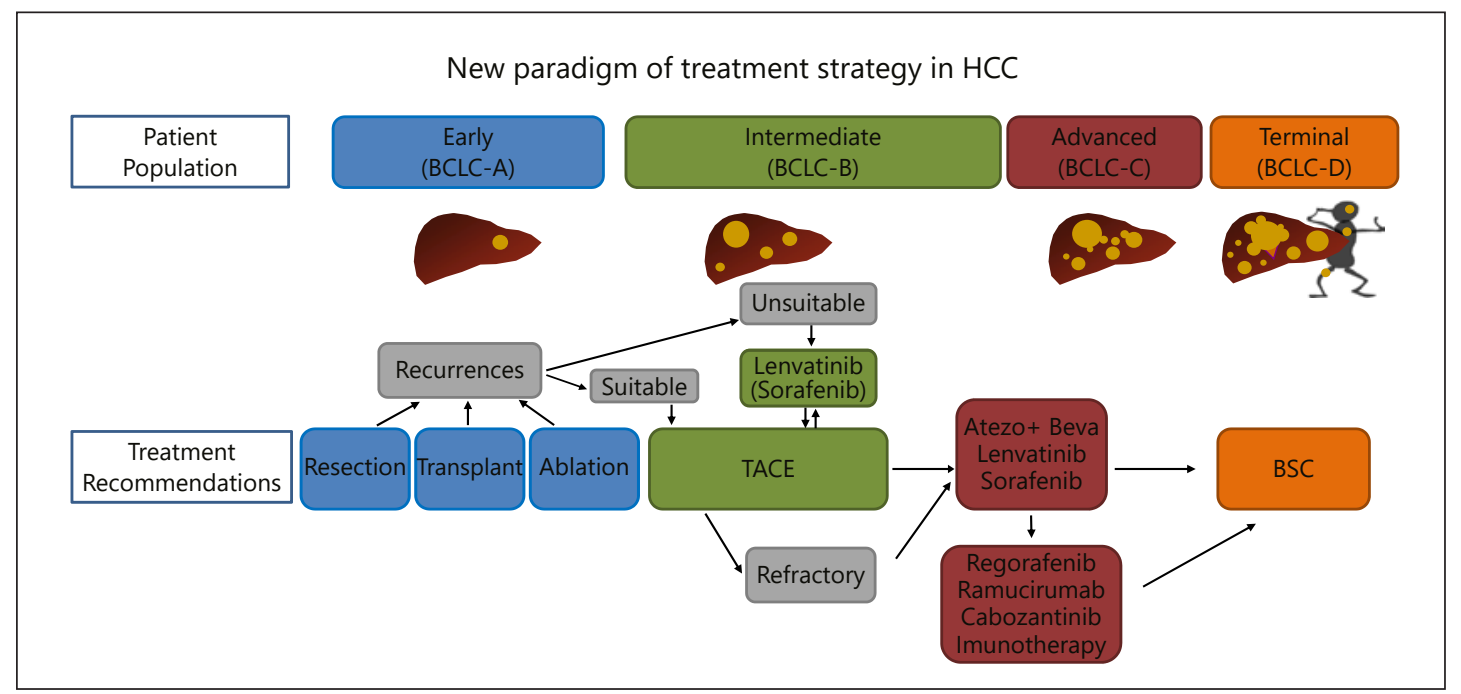

Fig. 2. New paradigm of treatment strategy in HCC. In intermediate-stage HCC, which is unsuitable for TACE, systemic therapy with high response rate such as lenvatinib may be a treatment choice instead of first-line TACE. BCLC-A to -D, Barcelona Clinic liver cancer stages A-D; atezo, atezolizumab; beva, bevacizumab; BSC, best supportive care.

In the TACTICS trial, sorafenib was introduced 2-3 weeks before the first TACE, resulting in normalization of abnormal tumor vessels. This increased the efficacy of TACE by improving the efficiency of drug delivery. In addition, pretreatment with sorafenib might decrease hypoxiainducible cytokines, such as vascular endothelial growth factor (VEGF) or angiopoietin 2. 


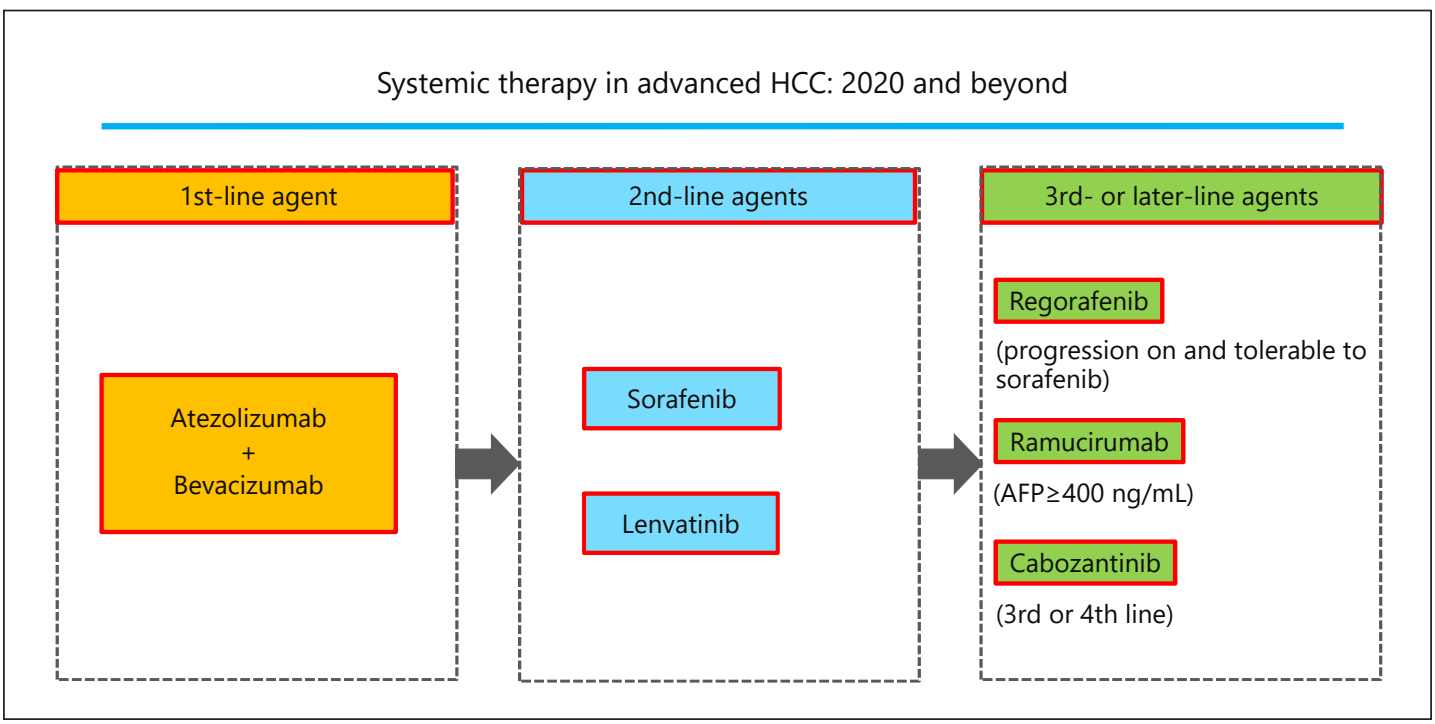

Fig. 3. Systemic therapy in advanced HCC: 2020 and beyond. Success of phase III IMbrave150 trial will bring the atezolizumab plus bevacizumab combination therapy as first-line therapy. AFP, $\alpha$-fetoprotein.

The concept of TACE-unsuitable HCC has also been gaining attention in recent years [47, 48]. This covers 3 patient types: (1) patients prone to becoming refractory to TACE, (2) patients whose hepatic functional reserve is likely to drop to Child-Pugh B on TACE, and (3) patients basically resistant to TACE [49]. Patients who do not meet the up-to-seven criteria would fall under the first 2 categories [49]. The use of lenvatinib as the initial treatment produces 3 main effects in such patients: it (1) downstages the tumor by inducing necrosis, (2) inhibits progression and metastasis by decreasing the release of VEGF, and (3) increases the effectiveness of TACE by improving the delivery of Lipiodol mixed with anticancer drugs due to normalization of the tumor vasculature. In fact, lenvatinib-TACE sequential therapy significantly extends survival compared with TACE alone in patients who do not meet the up-toseven criteria [47], and this sequential therapy is gradually becoming the routine approach for TACE-unsuitable patients in Japan [29, 48] (Fig. 1, 2). It is logical that pretreatment with lenvatinib followed by superselective TACE would preserve liver function and increase the response to TACE, improving overall survival compared with nonselective TACE as the first-line treatment for intermediate-stage HCC patients whose tumor burden is beyond the up-toseven criteria. Among several targeted agents, lenvatinib has the highest overall response rate (41\% in the REFLECT trial and 62\% [50] in intermediate-stage HCC from the subanalysis of the REFLECT trial). This is better than the overall response rate of TACE, which was $41 \%$ in the placebo arm of the world largest TACE combination study, the BRISK-TA trial [41].

\section{Paradigm Change in Advanced HCC}

Trends in the use of immune checkpoint inhibitors in patients with advanced HCC have been another major topic of interest recently. Unfortunately, clinical trials of nivolumab as first-line therapy [15] and pembrolizumab monotherapy as second-line therapy [28] both failed. However, there was a successful trial investigating the combination of the anti-PD-L1 antibody atezolizumab with the anti-VEGF antibody bevacizumab, and its results were published in 2020 [17]. The trial was conducted to test the hypothesis that bevacizumab would 


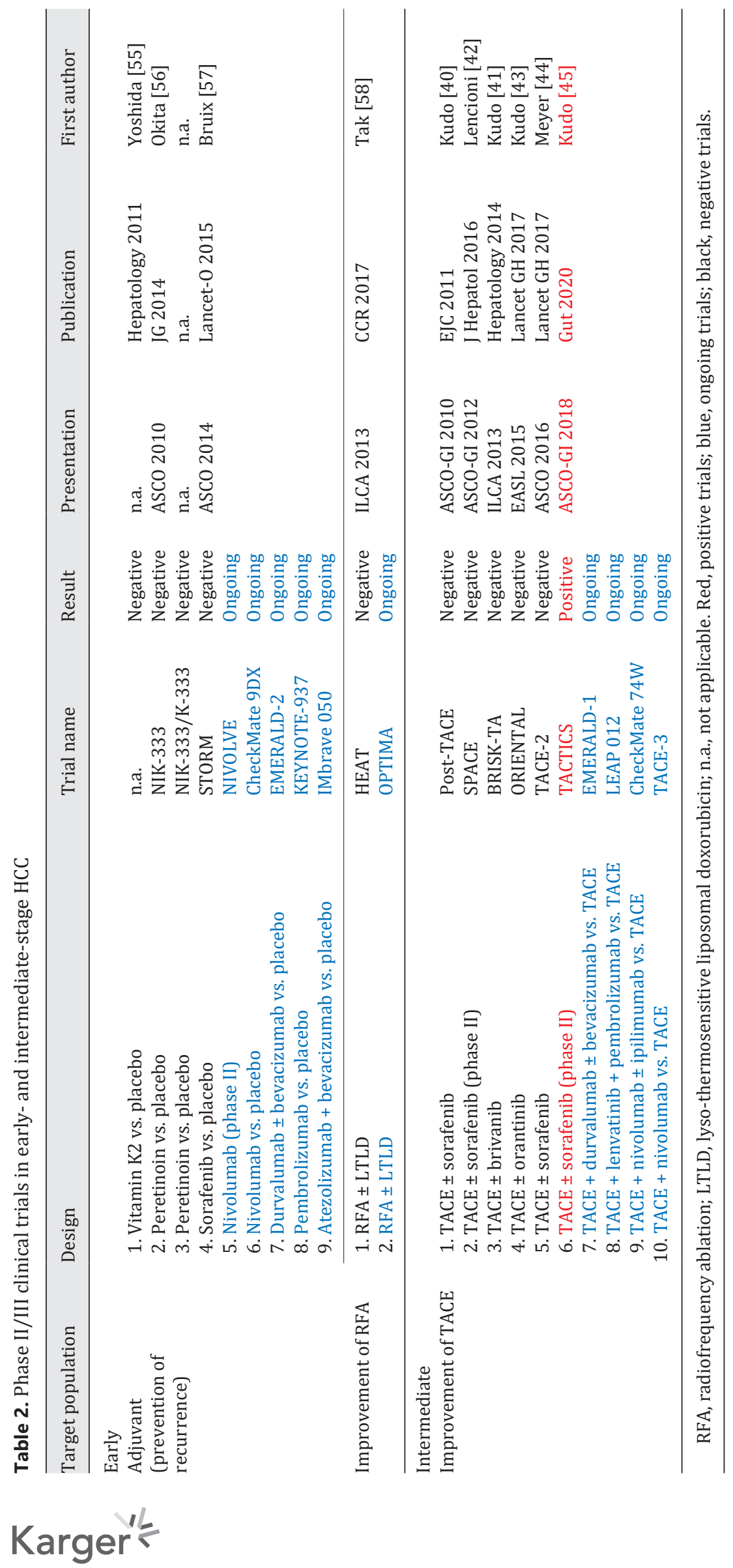




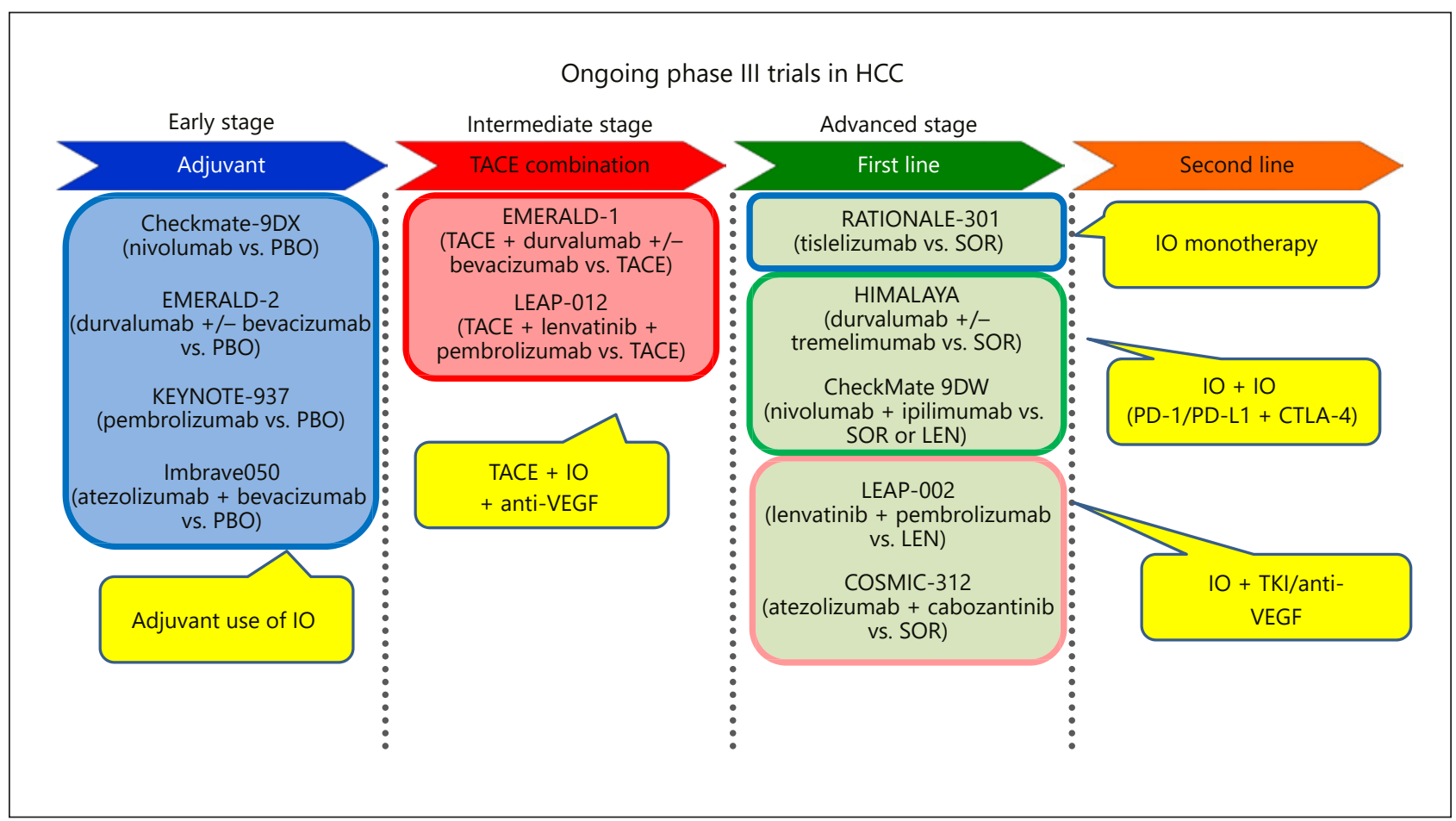

Fig. 4. Ongoing phase III trials in HCC. Several combination trials with immune checkpoint inhibitors are ongoing in early-, intermediate-, and advanced-stage HCC. PBO, placebo; IO, immuno-oncology; SOR, sorafenib; LEN, lenvatinib; VEGF, vascular endothelial growth factor; PD-L1, programmed cell death ligand 1; CTLA-4, cytotoxic T-lymphocyte-associated protein 4; TKI, tyrosine kinase inhibitor.

increase the activation of CD8+ T cells by reversing the immunosuppressive effects of VEGF, which basically induces immunosuppressive cells such as regulatory $\mathrm{T}$ cells, tumor-associated macrophages, and myeloid-derived suppressor cells. Thus, atezolizumab plus bavacizumab combination therapy increases cytotoxicity against tumor cells [51-54]. The data generated appear to support this hypothesis. No other systemic treatment option has been shown to extend overall survival compared with sorafenib over the past 12 years, but the first interim analysis for this phase III IMbrave150 trial demonstrated the superiority of the new regimen with respect to both overall survival and progression-free survival [17]. Once combination immunotherapy with atezolizumab and bevacizumab is approved, it seems likely that it will become established as the first-line therapy for advanced HCC (Fig. 3). Currently used drugs will likely be shifted to later lines of treatment (Fig. 3), with first-line drugs (sorafenib and lenvatinib) becoming second-line therapies and current second-line therapies (regorafenib, ramucirumab, and cabozantinib) becoming third-line options. This would represent a marked shift in the paradigm for treatment of advanced HCC.

\section{Ongoing Clinical Trials}

Clinical trials of adjuvants for early-stage HCC treated by resection or radiofrequency ablation are ongoing, as are many clinical trials investigating the combination of TACE and an immune checkpoint inhibitor with or without an anti-VEGF antibody (Table 2; Fig. 4) [40-45, 55-58]. Of course, trials investigating monotherapy with immune checkpoint inhibitors and combination therapy with multiple immune checkpoint inhibitors (an anti-PD-1 or PD-L1 
antibody plus an anti-CTLA-4 antibody) are ongoing for advanced HCC, as are phase III trials investigating combinations of anti-PD-1/PD-L1 antibodies with tyrosine kinase inhibitors (Table 2; Fig. 4) [4-28]. In other words, trials of immune checkpoint inhibitors are ongoing for all stages of HCC. If these trials succeed, a true paradigm change will occur and treatment outcomes for HCC will be greatly improved.

\section{Preservation of Liver Function Is Essential}

It bears repeating that as an increasing number of new effective treatment regimens emerge, there will likely be even greater demand to stop ineffective TACE that decreases the liver function, even though it was once the only treatment recommended by practice guideline for intermediate-stage HCC. The main objective when treating intermediate-stage HCC is to achieve a good response while preserving the hepatic functional reserve. Therefore, when treating patients who are unsuitable for TACE, it is important to stop TACE early or start systemic therapy first followed by selective TACE with curative intent $[47,48]$, which will both increase the efficacy of TACE and minimize the deterioration of liver function. Preservation of liver function is, therefore, essential for improving treatment outcomes in HCC, and avoiding overuse of TACE is vital in intermediatestage HCC. The key goal for the treatment of HCC going forward will be preservation of liver function.

In the era of multiple effective systemic therapies, including combination immunotherapy regimens, it will be important to determine how to select the best treatment for a given patient. Expert physicians in the field of HCC management should always keep in mind that preservation of liver function is the most important issue when considering treatment strategies in clinical practice.

\section{Disclosure Statement}

Lectures: Eisai, Bayer, MSD, Bristol-Myers Squibb, Lilly, EA Pharma. Grants: Gilead Sciences, Taiho, Sumitomo Dainippon Pharma, Takeda, Otsuka, EA Pharma, Abbvie, Eisai. Advisory role: Eisai, Ono, MSD, Bristol-Myers Squibb, Rochep.

\section{Author Contributions}

M. Kudo conceived, wrote, and approved the final paper.

\section{References}

1 Kudo M. Management of Hepatocellular Carcinoma in Japan as a World-Leading Model. Liver Cancer. 2018 May;7(2):134-47.

2 Kudo M, Lencioni R, Marrero JA, Venook AP, Bronowicki JP, Chen XP, Dagher L, Furuse J, Geschwind JF, Ladron de Guevara L, Papandreou C, Sanyal AJ, Takayama T, Yoon SK, Nakajima K, Lehr R, Heldner S, Ye SL. Regional differences in sorafenib-treated patients with hepatocellular carcinoma: GIDEON observational study. Liver Int. 2016;36:1196-205.

3 Kudo M, Izumi N, Kubo S, Kokudo N, Sakamoto M, Shiina S, Tateishi R, Nakashima O, Murakami T, Matsuyama Y, Takahashi A, Miyata H, Takayama T. Report of the 20th nationwide follow-up survey of primary liver cancer in Japan. Hepatol Res. 2020;50:15-46.

4 Kudo M, Ueshima K, Yokosuka O, Ogasawara S, Obi S, Izumi N, et al.; SILIUS study group. Sorafenib plus low-dose cisplatin and fluorouracil hepatic arterial infusion chemotherapy versus sorafenib alone in patients with advanced hepatocellular carcinoma (SILIUS): a randomised, open label, phase 3 trial. Lancet Gastroenterol Hepatol. 2018 Jun;3(6):424-32.

5 Llovet JM, Ricci S, Mazzaferro V, Hilgard P, Gane E, Blanc JF, et al; SHARP Investigators Study Group. Sorafenib in advanced hepatocellular carcinoma. N Engl J Med. 2008 Jul;359(4):378-90. 


\begin{tabular}{|c|c|}
\hline Liver Cancer 2020;9:367-3 & \\
\hline DOI: 10.1159/000507934 & $\begin{array}{l}\text { (c) } 2020 \text { The Author(s). Published by S. Karger AG, Basel } \\
\text { www.karger.com/lic }\end{array}$ \\
\hline
\end{tabular}

6 Cheng AL, Kang YK, Chen Z, Tsao CJ, Qin S, Kim JS, et al. Efficacy and safety of sorafenib in patients in the AsiaPacific region with advanced hepatocellular carcinoma: a phase III randomised, double-blind, placebocontrolled trial. Lancet Oncol. 2009 Jan;10(1):25-34.

7 Cheng AL, Kang YK, Lin DY, Park JW, Kudo M, Qin S, et al. Sunitinib versus sorafenib in advanced hepatocellular cancer: results of a randomized phase III trial. J Clin Oncol. 2013 Nov;31(32):4067-75.

8 Zhu AX, Rosmorduc O, Evans TR, Ross PJ, Santoro A, Carrilho FJ, et al. SEARCH: a phase III, randomized, doubleblind, placebo-controlled trial of sorafenib plus erlotinib in patients with advanced hepatocellular carcinoma. J Clin Oncol. 2015 Feb;33(6):559-66.

9 Johnson PJ, Qin S, Park JW, Poon RT, Raoul JL, Philip PA, et al. Brivanib versus sorafenib as first-line therapy in patients with unresectable, advanced hepatocellular carcinoma: results from the randomized phase III BRISK-FL study. J Clin Oncol. 2013 Oct;31(28):3517-24.

10 Cainap C, Qin S, Huang WT, Chung IJ, Pan H, Cheng Y, et al. Linifanib versus Sorafenib in patients with advanced hepatocellular carcinoma: results of a randomized phase III trial. J Clin Oncol. 2015 Jan;33(2):172-9.

11 Abou-Alfa GK, Shi Q, Knox JJ, Kaubisch A, Niedzwiecki D, Posey J, et al. Assessment of Treatment With Sorafenib Plus Doxorubicin vs Sorafenib Alone in Patients With Advanced Hepatocellular Carcinoma: Phase 3 CALGB 80802 Randomized Clinical Trial. JAMA Oncol. 2019 Sep;5(11):1582-8.

12 Vilgrain V, Pereira H, Assenat E, Guiu B, Ilonca AD, Pageaux GP, et al.; SARAH Trial Group. Efficacy and safety of selective internal radiotherapy with yttrium-90 resin microspheres compared with sorafenib in locally advanced and inoperable hepatocellular carcinoma (SARAH): an open-label randomised controlled phase 3 trial. Lancet Oncol. 2017 Dec;18(12):1624-36.

13 Chow PK, Gandhi M, Tan SB, Khin MW, Khasbazar A, Ong J, et al.; Asia-Pacific Hepatocellular Carcinoma Trials Group. SIRveNIB: Selective Internal Radiation Therapy Versus Sorafenib in Asia-Pacific Patients With Hepatocellular Carcinoma. J Clin Oncol. 2018 Jul;36(19):1913-21.

14 Kudo M, Finn RS, Qin S, Han KH, Ikeda K, Piscaglia F, et al. Lenvatinib versus sorafenib in first-line treatment of patients with unresectable hepatocellular carcinoma: a randomised phase 3 non-inferiority trial. Lancet. 2018 Mar;391(10126):1163-73.

15 Yau T, Park JW, Finn RS, Cheng AL, Mathurin P, Edeline J, et al. CheckMate 459: a randomized, multi-center phase III study of nivolumab vs sorafenib as first-line treatment in patients with advanced hepatocellular carcinoma. Ann Oncol. 2019;30 Suppl 5:v874-5.

16 Ricke J, Klümpen HJ, Amthauer H, Bargellini I, Bartenstein P, de Toni EN, et al. Impact of combined selective internal radiation therapy and sorafenib on survival in advanced hepatocellular carcinoma. J Hepatol. 2019 Dec;71(6):1164-74.

17 Finn RS, Qin S, Ikeda M, Galle PR, Ducreux M, Kim TY, et al.; IMbrave150 Investigators. Atezolizumab plus Bevacizumab in Unresectable Hepatocellular Carcinoma. N Engl J Med. 2020 May;382(20):1894-905.

18 Llovet JM, Decaens T, Raoul JL, Boucher E, Kudo M, Chang C, et al. Brivanib in patients with advanced hepatocellular carcinoma who were intolerant to sorafenib or for whom sorafenib failed: results from the randomized phase III BRISK-PS study. J Clin Oncol. 2013 Oct;31(28):3509-16.

19 Zhu AX, Kudo M, Assenat E, Cattan S, Kang YK, Lim HY, et al. Effect of everolimus on survival in advanced hepatocellular carcinoma after failure of sorafenib: the EVOLVE-1 randomized clinical trial. JAMA. 2014 Jul;312(1):57-67.

20 Zhu AX, Park JO, Ryoo BY, Yen CJ, Poon R, Pastorelli D, et al.; REACH Trial Investigators. Ramucirumab versus placebo as second-line treatment in patients with advanced hepatocellular carcinoma following first-line therapy with sorafenib (REACH): a randomised, double-blind, multicentre, phase 3 trial. Lancet Oncol. 2015 Jul;16(7):859-70.

21 Kudo M, Moriguchi M, Numata K, Hidaka H, Tanaka H, Ikeda M, et al. S-1 versus placebo in patients with sorafenib-refractory advanced hepatocellular carcinoma (S-CUBE): a randomised, double-blind, multicentre, phase 3 trial. Lancet Gastroenterol Hepatol. 2017 Jun;2(6):407-17.

22 Abou-Alfa GK, Qin S, Ryoo BY, Lu SN, Yen CJ, Feng YH, et al. Phase III randomized study of second line ADI-PEG 20 plus best supportive care versus placebo plus best supportive care in patients with advanced hepatocellular carcinoma. Ann Oncol. 2018 Jun;29(6):1402-8.

23 Bruix J, Qin S, Merle P, Granito A, Huang YH, Bodoky G, et al.; RESORCE Investigators. Regorafenib for patients with hepatocellular carcinoma who progressed on sorafenib treatment (RESORCE): a randomised, doubleblind, placebo-controlled, phase 3 trial. Lancet. 2017 Jan;389(10064):56-66.

24 Rimassa L, Assenat E, Peck-Radosavljevic M, Pracht M, Zagonel V, Mathurin P, et al. Tivantinib for second-line treatment of MET-high, advanced hepatocellular carcinoma (METIV-HCC): a final analysis of a phase 3, randomised, placebo-controlled study. Lancet Oncol. 2018 May;19(5):682-93.

25 Merle P, Blanc JF, Phelip JM, Pelletier G, Bronowicki JP, Touchefeu Y, et al.; RELIVE Investigators. Doxorubicin-loaded nanoparticles for patients with advanced hepatocellular carcinoma after sorafenib treatment failure (RELIVE): a phase 3 randomised controlled trial. Lancet Gastroenterol Hepatol. 2019 Jun;4(6):454-65.

26 Abou-Alfa GK, Meyer T, Cheng AL, El-Khoueiry AB, Rimassa L, Ryoo BY, et al. Cabozantinib in Patients with Advanced and Progressing Hepatocellular Carcinoma. N Engl J Med. 2018 Jul;379(1):54-63.

27 Zhu AX, Kang YK, Yen CJ, Finn RS, Galle PR, Llovet JM, et al.; REACH-2 study investigators. Ramucirumab after sorafenib in patients with advanced hepatocellular carcinoma and increased $\alpha$-fetoprotein concentrations (REACH-2): a randomised, double-blind, placebo-controlled, phase 3 trial. Lancet Oncol. 2019 Feb;20(2):282-96. 
28 Finn RS, Ryoo BY, Merle P, Kudo M, Bouattour M, Lim HY, et al.; KEYNOTE-240 investigators. Pembrolizumab As Second-Line Therapy in Patients With Advanced Hepatocellular Carcinoma in KEYNOTE-240: ARandomized, Double-Blind, Phase III Trial. J Clin Oncol. 2020 Jan;38(3):193-202.

29 Kokudo N, Takemura N, Hasegawa K, Takayama T, Kubo S, Shimada M, Nagano H, Hatano E, Izumi N, Kaneko S, Kudo M, Iijima H, Genda T, Tateishi R, Torimura T, Igaki H, Kobayashi S, Sakurai H, Murakami T, Watadani T, Matsuyama Y. Clinical practice guidelines for hepatocellular carcinoma: the Japan Society of Hepatology 2017 (4th JSH-HCC guidelines) 2019 update. Hepatol Res. 2019 Oct;49(10):1109-13.

30 Kudo M, Izumi N, Kokudo N, Matsui O, Sakamoto M, Nakashima O, et al.; HCC Expert Panel of Japan Society of Hepatology. Management of hepatocellular carcinoma in Japan: Consensus-Based Clinical Practice Guidelines proposed by the Japan Society of Hepatology (JSH) 2010 updated version. Dig Dis. 2011;29(3): 339-64.

31 Kudo M, Matsui O, Izumi N, Kadoya M, Okusaka T, Miyayama S, et al.; Liver Cancer Study Group of Japan. Transarterial chemoembolization failure/refractoriness: JSH-LCSGJ criteria 2014 update. Oncology. 2014;87 Suppl 1:22-31.

32 Raoul JL, Gilabert M, Piana G. How to define transarterial chemoembolization failure or refractoriness: a European perspective. Liver Cancer. 2014 May;3(2):119-24.

33 Cheng AL, Amarapurkar D, Chao Y, Chen PJ, Geschwind JF, Goh KL, Han KH, Kudo M, Lee HC, Lee RC, Lesmana LA, Lim HY, Paik SW, Poon RT, Tan CK, Tanwandee T, Teng G, Park JW. Re-evaluating transarterial chemoembolization for the treatment of hepatocellular carcinoma: consensus recommendations and review by an international expert panel. Liver Int. 2014;34:174-183.

34 Management consensus guideline for hepatocellular carcinoma: 2016 updated by the Taiwan Liver Cancer Association and the Gastroenterological Society of Taiwan. J Formos Med Assoc/Taiwan Yi Zhi. 2018;117: 381-403.

35 Korean Liver Cancer Association KL, National Cancer Center NC; Korean Liver Cancer Association; National Cancer Center. 2018 Korean Liver Cancer Association-National Cancer Center Korea Practice Guidelines for the Management of Hepatocellular Carcinoma. Gut Liver. 2019 May;13(3):227-99.

36 Ogasawara S, Chiba T, Ooka Y, Kanogawa N, Motoyama T, Suzuki E, et al. Efficacy of sorafenib in intermediatestage hepatocellular carcinoma patients refractory to transarterial chemoembolization. Oncology. 2014; $87(6): 330-41$

37 Arizumi T, Ueshima K, Chishina H, Kono M, Takita M, Kitai S, et al. Validation of the criteria of transcatheter arterial chemoembolization failure or refractoriness in patients with advanced hepatocellular carcinoma proposed by the LCSGJ. Oncology. 2014;87(s1 Suppl 1):32-6.

38 Peck-Radosavljevic M, Kudo M, Raoul J, et al. Outcomes of patients (pts) with hepatocellular carcinoma (HCC) treated with transarterial chemoembolization (TACE): global OPTIMIS final analysis. J Clin Oncol. 2018; 36(Suppl): abstr 4018.

39 Peck-Radosavljevic M, Lee HC, Kudo M, et al. Practice patterns and outcomes of transarterial chemoembolization in patients with hepatocellular carcinoma who were either ineligible or eligible for transarterial chemoembolization at inclusion: global OPTIMIS exploratory analysis. EASL, April 10-14, 2019, Vienna, Austria, abstr FRI-494.

40 Kudo M, Imanaka K, Chida N, Nakachi K, Tak WY, Takayama T, Yoon JH, Hori T, Kumada H, Hayashi N, Kaneko S, Tsubouchi H, Suh DJ, Furuse J, Okusaka T, Tanaka K, Matsui O, Wada M, Yamaguchi I, Ohya T, Meinhardt G, Okita K. Phase III study of sorafenib after transarterial chemoembolisation in Japanese and Korean patients with unresectable hepatocellular carcinoma. Eur J Cancer. 2011;47:2117-27.

41 Kudo M, Han G, Finn RS, Poon RT, Blanc JF, Yan L, et al. Brivanib as adjuvant therapy to transarterial chemoembolization in patients with hepatocellular carcinoma: A randomized phase III trial. Hepatology. 2014 Nov; 60(5):1697-707.

42 Lencioni R, Llovet JM, Han G, Tak WY, Yang J, Guglielmi A, et al. Sorafenib or placebo plus TACE with doxorubicin-eluting beads for intermediate stage HCC: the SPACE trial. J Hepatol. 2016 May;64(5):1090-8.

43 Kudo M, Cheng AL, Park JW, Park JH, Liang PC, Hidaka H, et al. Orantinib versus placebo combined with transcatheter arterial chemoembolisation in patients with unresectable hepatocellular carcinoma (ORIENTAL): a randomised, double-blind, placebo-controlled, multicentre, phase 3 study. Lancet Gastroenterol Hepatol. 2018 Jan;3(1):37-46.

44 Meyer T, Fox R, Ma YT, Ross PJ, James MW, Sturgess R, et al. Sorafenib in combination with transarterial chemoembolisation in patients with unresectable hepatocellular carcinoma (TACE 2): a randomised placebocontrolled, double-blind, phase 3 trial. Lancet Gastroenterol Hepatol. 2017 Aug;2(8):565-75.

45 Kudo M, Ueshima K, Ikeda M, Torimura T, Tanabe N, Aikata H, et al.; TACTICS study group. Randomised, multicentre prospective trial of transarterial chemoembolisation (TACE) plus sorafenib as compared with TACE alone in patients with hepatocellular carcinoma: TACTICS trial. Gut. 2019 Dec; gutjnl-2019-318934.

46 Kudo M. Proposal of Primary Endpoints for TACE Combination Trials with Systemic Therapy: Lessons Learned from 5 Negative Trials and the Positive TACTICS Trial. Liver Cancer. 2018 Sep;7(3):225-34.

47 Kudo M, Ueshima K, Chan S, Minami T, Chishina H, Aoki T, et al. Lenvatinib as an initial treatment in patients with intermediate-stage hepatocellular carcinoma beyond up-to-seven criteria and Child-Pugh A liver function: a proof-of-concept study. Cancers (Basel). 2019 Jul;11(8):11.

48 Kudo M. A New Treatment Option for Intermediate-Stage Hepatocellular Carcinoma with High Tumor Burden: Initial Lenvatinib Therapy with Subsequent Selective TACE. Liver Cancer. 2019 Oct;8(5):299-311. 


\section{Liver Cancer}

49 Kudo M, Han KH, Ye SL, Zhou J, Huang YH, Lin SM, et al. A changing paradigm for the treatment of Intermediate-stage hepatocellular carcinoma: APPLE Expert Consensus Statement. Liver Cancer. 2020; Epub ahead of print.

50 Yamashita T, Kudo M, Ikeda K, Izumi N, Tateishi R, Ikeda M, et al. REFLECT-a phase 3 trial comparing efficacy and safety of lenvatinib to sorafenib for the treatment of unresectable hepatocellular carcinoma: an analysis of Japanese subset. J Gastroenterol. 2020 Jan;55(1):113-22.

51 Kudo M. Combination Cancer Immunotherapy in Hepatocellular Carcinoma. Liver Cancer. 2018 Mar;7(1): 20-7.

52 Lu LC, Lee YH, Chang CJ, Shun CT, Fang CY, Shao YY, et al. Increased Expression of Programmed Death-Ligand 1 in Infiltrating Immune Cells in Hepatocellular Carcinoma Tissues after Sorafenib Treatment. Liver Cancer. 2019 Mar;8(2):110-20.

53 Ou DL, Lin YY, Hsu CL, Lin YY, Chen CW, Yu JS, et al. Development of a PD-L1-Expressing Orthotopic Liver Cancer Model: Implications for Immunotherapy for Hepatocellular Carcinoma. Liver Cancer. 2019 May;8(3):155-71.

54 Kudo M. A new era in systemic therapy for hepatocellular carcinoma: atezolizumab plus bevacizumab combination therapy. Liver Cancer. 2020. DOI: 101159/000505189. Epub.

55 Yoshida H, Shiratori Y, Kudo M, Shiina S, Mizuta T, Kojiro M, et al. Effect of vitamin K2 on the recurrence of hepatocellular carcinoma. Hepatology. 2011 Aug;54(2):532-40.

56 Okita K, Izumi N, Matsui O, Tanaka K, Kaneko S, Moriwaki H, et al.; Peretinoin Study Group. Peretinoin after curative therapy of hepatitis C-related hepatocellular carcinoma: a randomized double-blind placebocontrolled study. J Gastroenterol. 2015 Feb;50(2):191-202.

57 Bruix J, Takayama T, Mazzaferro V, Chau GY, Yang J, Kudo M, et al.; STORM investigators. Adjuvant sorafenib for hepatocellular carcinoma after resection or ablation (STORM): a phase 3, randomised, double-blind, placebo-controlled trial. Lancet Oncol. 2015 Oct;16(13):1344-54.

58 Tak WY, Lin SM, Wang Y, Zheng J, Vecchione A, Park SY. Phase III HEAT Study adding lyso-thermosensitive liposomal doxorubicin to radiofrequency ablation in patients with unresectable hepatocellular carcinoma lesions. Clin Cancer Res. 2018;24:73-83. 